\title{
THE HARMONIC SCALPEL APPLICATION IN THYROID SURGERY
}

\author{
Rumen Nenkov, Radoslav Radev, Ekaterina Marinova, Nikolay Cvetkov, Anatoli \\ Semkov, Borislav Petrov \\ Department of Thoracic surgery, UMHAT "St. Marina", \\ Medical University of Varna, Bulgaria.
}

\begin{abstract}
:
New, modern devices for tissue resection have been introduced in the surgical treatment of thyroid diseases recent years.

Aim: To present our experience with the use of the harmonic scalpel in thyroid surgery.

Patients and methods: For the period 2008 2011, 1398 patients (6 to 74 years old) with various thyroid deseases were operated on in our clinic. The resection was performed through a classic Kocher's collar incision in 583 patients, using minimally ivasive open access in 641 patients and with video-assisted technique in 174 patients. In all patients a harmonic scalpel device (Ethicon Endosurgery Care Inc) has been used. The length of surgical incision, use of haemostatic instruments and ligatures, extent of resection, need of draining, operative time, intra- and postoperative complications, length of postoperative hospital stay have been examined .
\end{abstract}

Results: The volume of resection ranged from istmusectomy to total thyroidectomy. During all operation haemostatic instruments and ligatures have not been used. Lack of bleeding and shortend operating time - up to $45 \%$ were found. The use of draining is significantly reduced, regardless of the extent of resection. There was no increase in the incidence of intra- and postoperative complications. The postoperative stay was significantly reduced.

Conclusion: In our opinion, the introduction in use of the harmonic scalpel changes the face of modern thyroid surgery providing reliable hemostasis and shortening the operating time significantly.

Key words: Thyroid surgery, harmonic scalpel.

\section{AIM:}

The conventional thyroid resections are linked with the mandatory use of many haemostatic instruments and vascular ligations, which leads to a significant increase in the operation time, as well as to severe tissue injuries.
As a rule, these operations require the placement of one or more drains in the thyroid place.

In recent years, new methods have been introduced in the field of thyroid surgery, such as minimally invasive, video-assisted and open approach techniques, with different access points. They all aim to minimize thyroid tissue trauma while preserving comparable efficiency and safety and providing better cosmetic results $1,2,3,4$. The implementation of these new techniques is linked with the development of new methods for tissue dissection and ligation of blood vessels such as harmonic scalpel and argon-plasma coagulator.

The objective of the current work is to present our experience with the use of harmonic scalpel in the surgery of thyroid gland.

\section{PATIENTS AND METHODS}

For the period from 2008 to 2011,1398 patients at the age between 6 to 74 years, with various thyroid deseases were operated on in our clinic. The resection was performed through a classic Kocher's collar incision in 583 patients, using minimally ivasive open access in 641 patients and with video-assisted method in 174 patients (table. 1).

Table. 1. Use of different surgical approaches in combination with harmonic scalpel.

\begin{tabular}{|l|c|c|}
\hline \multirow{2}{*}{ Surgical approach } & \multicolumn{2}{|c|}{ patients } \\
\cline { 2 - 3 } & $\mathrm{n}$ & $\%$ \\
\hline Classic Kocher incision & 583 & 41,7 \\
\hline Minimaly invasive open access & 641 & 45,9 \\
\hline Videoassisted technique & 174 & 12,4 \\
\hline Total & 1398 & 100 \\
\hline
\end{tabular}

All patients were operated on with the use of the harmonic scalpel of the company Ethicon Endo-Surgery Care (Fig.1). 


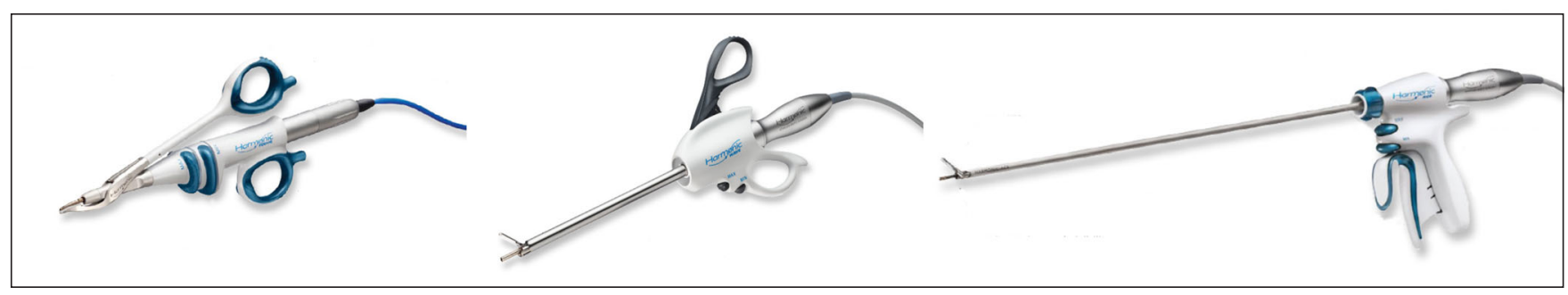

Fig.1. Ultrasound (Harmonic scalpel) handpiece devices used in our thyroid resections.

Using the afornamed devices, the strap muscles were devided then the intended extent of thyroid resection was performed, including the discontinuation of all thyroid vessels.

A comparetive examination of the following parameters was made: length of the surgical incision, use of haemostatic instruments, extent of thyroid resection, use of draining, operative time duration, intra-and postoperative complications, length of postoperative hospital stay.

\section{RESULTS}

The length of the operative incision in the patients group operated on through a classic cervical approach was between 3,5 and $4,5 \mathrm{~cm}$. In the group with minimally invasive open approach it was between 2 and $3 \mathrm{~cm}$. And the patients who underwent video-assisted resection had an incision between 1,5 and $2 \mathrm{~cm}$ in size (Fig.2).

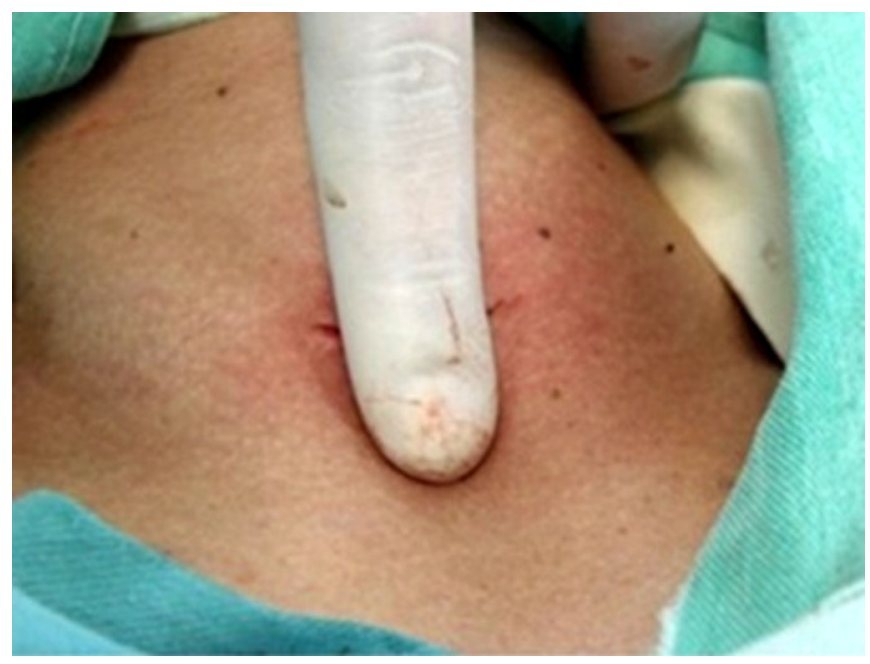

Fig.2: The length of incision with video-assisted surgery.

The extent of thyroid resection ranged from istmusectomy to thyroidectomy. All operations were preformed without need to use hemostatic instruments and ligatures. Figure 3 shows the complete equipment which is necessary to perform a thyroid resection with harmonic scalpel.

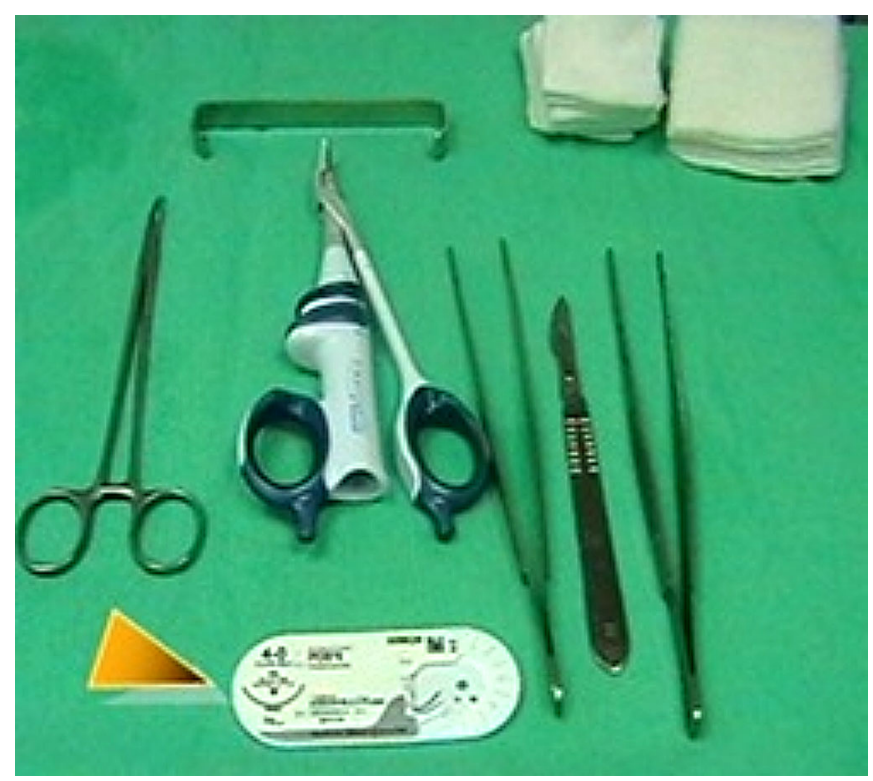

Fig.3: Instruments and sutures necessary to perform thyroid resection with harmonic scalpel.

Bleeding from the resected thyroid parenchyma or disrupted thyroid vessels was not observed. The operative time in all three groups was shortened with $45 \%$. Draining the thyroid bed was required much less than resection through conventional method.

The need of draining the thyroid bed was significantly reduced in comparison to the conventional technique, regardless of the volume of resection (Fig. 4). 


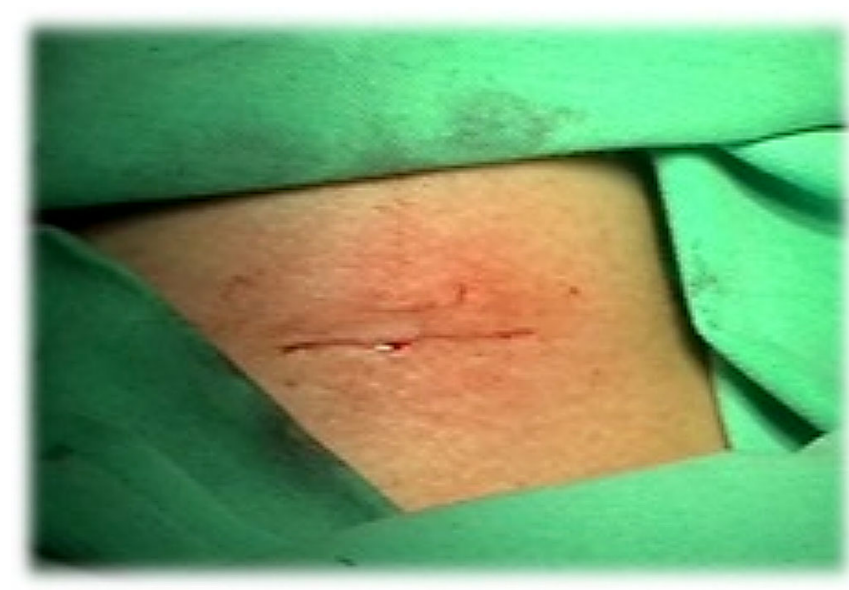

Fig.4: Thyroidectomy with harmonic scalpel using minimally invasive open approach, without use of draining.

There was no increase in the incidence of intraand postoperative complications. The length of the postoperative hospital stay was significally decreased. All patients were discharged in the first 8 to 24 postoperative hours.

\section{DISCUSSION}

The meticulous haemostasis is of crucial importance for the success of thyroid surgery. It prevents the intra- and postoperative complications and helps to improve the quality and shorten the postoperative hospital stay. The conventional thyroid resections, using Kocher's technique require a massive amount of instruments, mainly for placing ligatures. In recent years other tools as electrocautery, argon plasma coagulation, Ultrasicion and LigaSure as well as various clips have been introduced in thyroid surgery $5,6,7$.

The harmonic scalpel was developed in the early 90 's. An active titanium blade vibrates with a frequency 55000 cycles per second and is used to simultaneously cut and coagulate the tissues. The harmonic scalpel ensures safe and effective heamostasis for blood vessels in diameter up to $5 \mathrm{~mm}^{8}$. The sharp tip of the blade and the reduced heat generation permits to preserve the tissue and minimize the of the surrounding tissue injury 9 .

Several advantages of the harmonic scalpel, such as the minimized tissue trauma, reduced smoke production, avoidance of neuro-muscular stimulation and electricity conductance through the human's body, thrusted on the device in the field of modern thyroid surgery.
Our study includes patients with various thyroid diseases, which demonstrates the possibility to perform any extent of thyroid resection with improved anatomic dissection and visual control during the exploration of the gland and the surrounding structures in the neck.

Furthermore, in the absence of bleeding it is easily to find the underlying parathyroid glands and the nearby recurrent laryngeal nerve. The latter is precondition for lesser postoperative complications. Harmonic scalpel application permits to decrease the traction and manipulation of the thyroid, especially when dissecting and cutting the upper vascular pedicle of the gland. The improved control over the upper thyroid pole vessels acheaved with the harmonic scalpel leads to additional operative incision length reduction, especially with the video-assisted technique and as a consequence, improved cosmetic results $10,11,12,13$. The use of 30 degree, $5 \mathrm{~mm}$ optics makes easier to identify the parathyroid glands and recurrent laryngeal nerve and also to visualize the upper thyroid vessels before cutting them with harmonic scalpel. Our results demonstrate that the technique can be applied not only for solitary thyroid nodules but also for multynodular goiter. The most important determinant for the technique is the size of the dominant thyroid node and the size of thyroid lobe, because of the limited working space. We have accepted that the maximal lobe size should not exceed $7 \mathrm{~cm}$ in length and $3,5 \mathrm{~cm}$ in width. The volume of one thyroid lobe should not exceed $25 \mathrm{ml}$ on ultrasound examination. The reduced number of hemostatic instruments followed by decrease in placement of ligatures leads to operative time shortening up to $45 \%$ compared with the conventional resections as well as to reduced tissue trauma. Resulting in decreased transudation and exudation processes in the thyroid bed, all this helps to reduce the amount of fluid requiring draining and the need for placing drainage in the thyroid bed.

Our experience confirms significantly better postoperative pain control and fastend recovery for the patients where the harmonic scalpel has been used. The latter allows to shorten the postoperative hospital stay and to increase the planned patients admissions ${ }^{12}$.

\section{CONCLUSIONS}

Our results demonstrate that the harmonic scalpel is extremely safe and effective for surgical treatment of thyroid diseases. It allows extreamely good and reliable hemostasis, shortens the operative time, reduces the complications, fastens the recovery of the patient with improved pain control, reduced postoperative stay and improved cosmetic results 


\section{REFERENCES:}

1. Nenkov R, Radev R, Madzhov R. Minimally Invasive Open Access Thyoid Surgery - Main Point, Indications and Effectiveness. Surgery. 2009 LXV(1):24-27. [in Bulgarian]

2. Bellantone R, Lombardi CP, Raffaelli M, Rubino F, Boscherini M, Perilli W. Minimally invasive, totally gasless video-assisted thyroid lobectomy. Am J Surg. 1999 Apr;177(4): 342-343. [PubMed] [CrossRef]

3. Ikeda Y, Takami H, Tajima G, Sasaki Y, Takayama J, Kurihara H, et al. Total endoscopic thyroidectomy: axillary or anterior chest approach. Biomed Pharmacother. 200256 Suppl 1:72s-78s. [PubMed]

4. Miccoli P, Berti P, Bendinelli C, Conte M, Fasolini F, Martino E. Minimally invasive video-assisted surgery of the thyroid: a preliminary report. Langenbecks Arch Surg. 2000 Jul;385(4):261-264. [PubMed] [CrossRef]

5. Nenkov R, Radev R, Kuzmanov Y, Kornovski S, Kuzmanov S, Nanev B, et al. Argon plasma resection of the thyroid gland - nature and advantages. Surgery. 2005 LXI(3):19-22. [in Bulgarian]

6. Sartori PV, De Fina S, Colombo G, Pugliese F, Romano F, Cesana G, et al. Ligasure versus Ultracision in thyroid surgery: a prospective randomized study. Langenbecks Arch Surg. 2008 Sep;393(5):655-8. Epub 2008 Jul 22. [PubMed] [CrossRef]

7. He Q, Zhuang D, Zheng L, Zhou P, Chai J, Lv Z. Harmonic focus in total thyroidectomy plus level III-IV and VI dissection: a prospective randomized study. World J Surg Oncol. 2011 Oct 31;9:141. [PubMed] [CrossRef]

8. Siperstein AE, Berber E, Morkoyun E. The Use of the Harmonic Scalpel vs Conventional Knot Tying for Vessel Ligation in Thyroid Surgery. Arch Surg. 2002 Feb;137(2):137-142. [PubMed] [CrossRef]

9. Cordtn C, Fajardo R, Rammrez J, Herrera MF. A randomized, prospective, parallel group study comparing the harmonic scalpel to electrocautery in thyroidectomy. Surgery. 2005 Mar; 137(3):337-341. [PubMed] [CrossRef]

10. Ecker T, Carvalho AL, Choe JH, Walosek G, Preuss KJ. Hemostasis in thyroid surgery: harmonic scalpel versus other techniques-a metaanalysis. Otolaryngol Head Neck Surg. 2010 Jul;143(1):17-25. [PubMed] [CrossRef]

11. Foreman E, Aspinall S, Bliss RD, Lennard TW. The Use of the Harmonic Scalpel in Thyroidectomy: 'Beyond the Learning Curve'. Ann R Coll Surg Engl. 2009 Apr;91(3):214-216. [PubMed] [CrossRef]

12. Markogiannakis H, Kekis PB, Memos N, Alevizos L, Tsamis D, Michalopoulos NV, et al. Thyroid surgery with the new harmonic scalpel: a prospective randomized study. Surgery. 2011 Mar;149(3):411-5. Epub 2010 Sep 18. [PubMed] [CrossRef]

13. Miccoli P, Donatini G. Use of the Harmonic Scalpel in Thyroid Surgery Review of the Literature. European Endocrine Disease. 2006:54-58.

\author{
Address for correspondence: \\ Rumen Nenkov M.D., PhD \\ Clinic of Thoracic Surgery, UMHAT "St. Marina”, Varna \\ Medical University "Prof. Paraskev Stoyanov", Varna \\ 1, Hristo Smirnenski str., Varna, Bulgaria \\ E-mail: nenkovrn@hotmail.com;
}

http://www.journal-imab-bg.org 